\title{
Trombidioid (Acari: Parasitengona) Larva Derilerinin Değerlendirilmesi ve Teşhisteki Önemi
}

\author{
Evren BUĞA ${ }^{1 *}$ D, Sevgi SEVSAY ${ }^{2}$ \\ ${ }^{1}$ Erzincan Binali Yıldırım Üniversitesi, Fen Bilimleri Enstitüsü, Erzincan,Türkiye \\ ${ }^{2}$ Erzincan Binali Yıldırım Üniversitesi, Fen Edebiyat Fakültesi, Biyoloji Bölümü, Erzincan,Türkiye
}

Geliş / Received: 26/04/2019, Kabul / Accepted: 11/07/2019

Öz

Konak üzerinde parazit olan trombidioid larvası, yeteri kadar beslendikten sonra konaktan ayrılır ve protonimf (hareketsiz) safhasına, sonrasında larva derisini atarak deutonimf safhasına geçer. Bu çalışmada, konak üzerinden toplanan parazit larvalar ile konak üzerindeki diğer larvalardan elde edilen deutonimflerin aynı tür olduğu tespit edildi. Bu tespit, larvalar ile deutonimfe geçerken atılan larva derilerinin (exuviae) karşılaştırılmasıyla sağlandı. Bu yöntemle, bir otbiçen (Opilionida) ve iki sinek (Diptera) türü (Rhagio sp., Musca domestica) üzerinden toplanan parazit akarlardan, Allothrombium sp., Trichotrombidium muscarum (Riley, 1878) ve Trombidium holosericeum (Linnaeus, 1758) olmak üzere üç akar türü teşhis edildi. Aynı zamanda daha önceki çalışmalarda gözlenen ancak bugüne kadar üzerinde durulmayan larva derilerinin, larvalar ile aynı karakteristik özellikleri gösterdiği ve morfolojik teşhiste kullanılabileceği belirlendi.

Anahtar kelimeler. Acari, biyoloji, deri değiştirme, hayat evresi, Trombidioidea

\section{Evaluation of Trombidioid (Acari: Parasitengona) Larval Exuviae And Its Importance In Diagnosis}

\begin{abstract}
The larva of trombidioid which parasitic on host separates from host after enough feeding and pass to protonymph (inactive) stage, then it passes to deutonymph stage by leaving larva skin (exuviae). In this study, the parasitic larvae, which were collected from host and deutonymphs, which obtained from other larvae on host, were identified as the same species. This identification was achieved by the comparison of larvae and exuviae that has been released while passing deutonymph stage. With this method, three mite species, Allothrombium sp., Trichotrombidium muscarum (Riley, 1878), Trombidium holosericeum (Linnaeus, 1758) were diagnosed from samples collected from one harvestmen (Opilionida) and two fly (Diptera) species (Rhagio sp., Musca domestica). At the same time, it was determined that larval skins, observed in previous studies but not emphasized to date, showed the same characteristics as the larvae and could be used in morphological diagnosis.
\end{abstract}

Key words. Acari, biology, life cycle, moulting, Trombidioidea

\section{Giriş}

Parasitengona (Acari: Prostigmata) tür zenginliği, yaşadığ 1 biyotoplar ve yaşam tarzları bakımından en farklı taksonlardan biridir. Karasal parasitengona sirasiyla, yumurta, prelarva, larva, protonimf, deutonimf, tritonimf ve ergin olmak üzere yedi yaşam evresi geçirir (Şekil 1). 


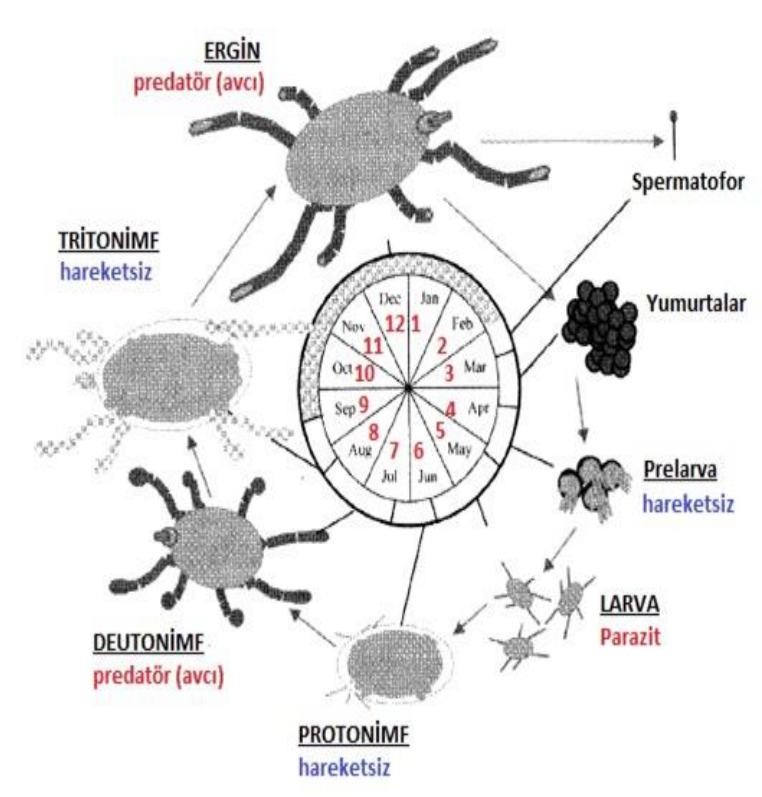

Şekil 1. Parasitengona'nın yaşam döngüsü (Wohltmann vd., 2007)

Heteromorfik hayat döngüsüne sahip olan bu grubun larva, deutonimf ve ergin dönemleri aktif iken diğer dönemleri aktif değildir. Larva evresi, genellikle parazit olarak konaklara tutunduğu ve beslendiği dönemdir. Deutonimf ve ergin dönemleri ise predatördür ve genel olarak bu iki evre larva sonrası dönem (postlarva) olarak adlandırılır (Wohltmann vd., 2006). Larva dönemi ile postlarva dönemlerinin morfolojik yapı ve özellikleri birbirinden tamamen farkl1 olmasindan dolayı her iki safha laboratuvar şartlarında gözlenmeden bugüne kadar verilen türlerin birçoğu bilgi kirliliğine neden olmuştur. Bu kirliliği, araziden canlı olarak erginlerin toplanıp, laboratuvar ortamında yumurtlatılıp larvaların elde edilmesi (Mąkol ve Sevsay, 2011) veya toplanan konaklar üzerindeki beslenmiş larvalardan, laboratuvar ortamında deutonimf oluşumunun sağlaması ile önlenebilir. (Wohltmann vd., 1996). Karasal parasitengonaya ait (Trombiculidae ve Walchiidae hariç) bugüne kadar yapılmış çalışmalarda 837 tür sadece larvadan, 891 tür postlarva safhasından, 135 tür ise her iki safhadan verilmiş olması, bu tür çalışmaların çok önemli olduğunu göstermektedir (Mąkol \& Wohltmann 2012, 2013; Sevsay 2017).

$\mathrm{Bu}$ çalışmanın amacı, doğadan konak üzerinde veya konaktan ayrılmış olarak toplanan parazit canlı akarların deutonimf evreye geçişini gözlemlemek ve atılan larva derilerinin morfolojik teşhiste kullanılabilirliğini göstermektir.

\section{Materyal ve Yöntem}

Atrapla doğadan canlı olarak toplanan konaklar üzerinden beslenmiş olan larvalar (Şekil 2.a) alınarak kömür-alçı (1:9) karışımı yaşam şişelerine konulmuştur. Günlük takibi yapılan beslenmiş larvalar 1-2 gün içinde aktif olmayan protonimf safhasına geçtiği (Şekil 2.b) ve daha sonra larva derisi altında oluşan bacaklar gözlemlenmiştir (Şekil 2.c). 

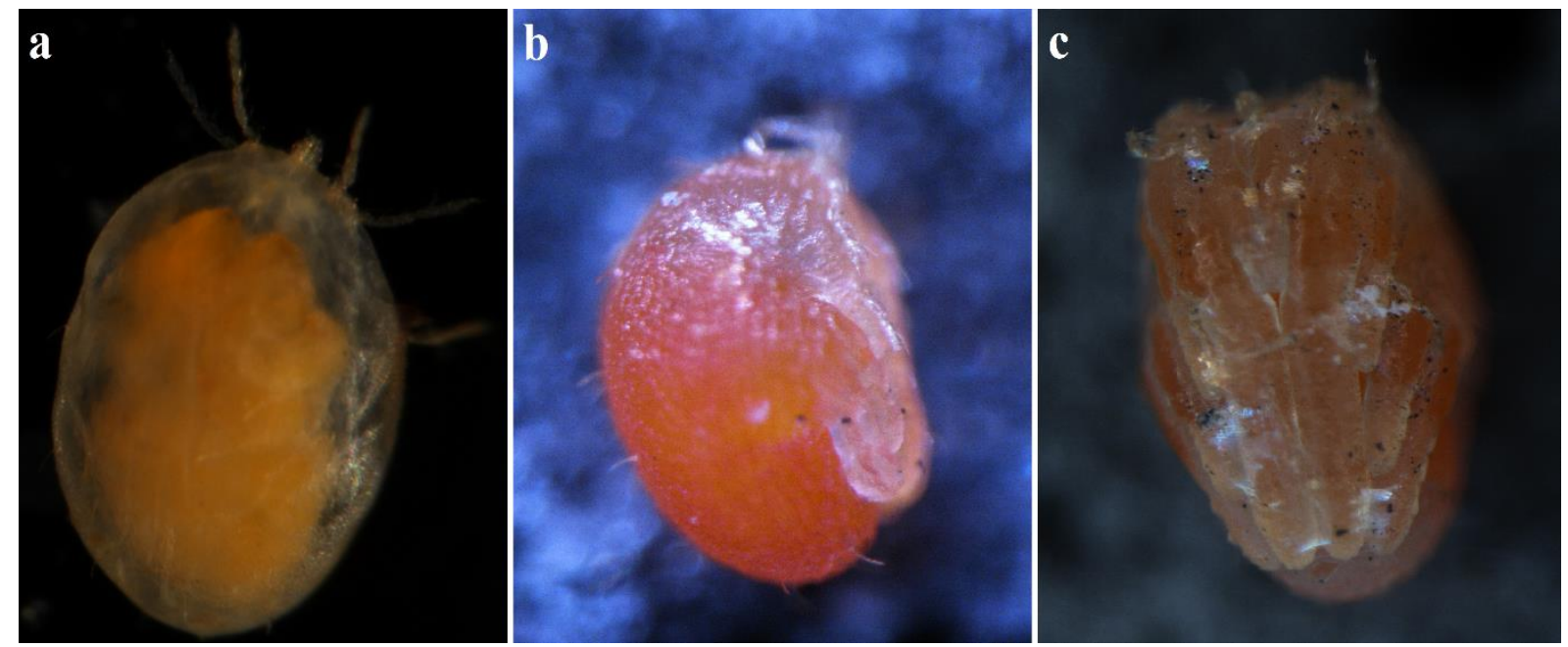

Şekil 2. Trombioidea; a. Beslenmiş larva, b. Protonimf erken evre, c. Protonimf geç evre

Yaklaşık 6-7 gün sonra larva derisini yırtarak (Şekil 3.a) yeni bir deriyle aktif deutonimf evresine geçmiştir (Şekil 3.b). Larvalar tarafindan birakılan kuru larva derileri yaşam şişesinden alınarak direkt Hoyer ortamında preparatları yapılmıştır (Walter ve Krantz, 2009). Deutonimf, larva derisinin içinden deriyi yırtarak çıktığı için (Robaux, 1974) deriler olabildiğince dikkatli alınmıştır. Konağın üzerindeki beslenmemiş larvalar \%70 etil alkole alınmış ve daha sonra 5-10 dakika kadar $\% 50$ laktik asitte bekletilerek Hoyer ortamında preparatları yapılmıştır. Larvadan deutonimfe dönüşen örnekler beslenemedikleri için daha sonraki evrelere geçememişlerdir.
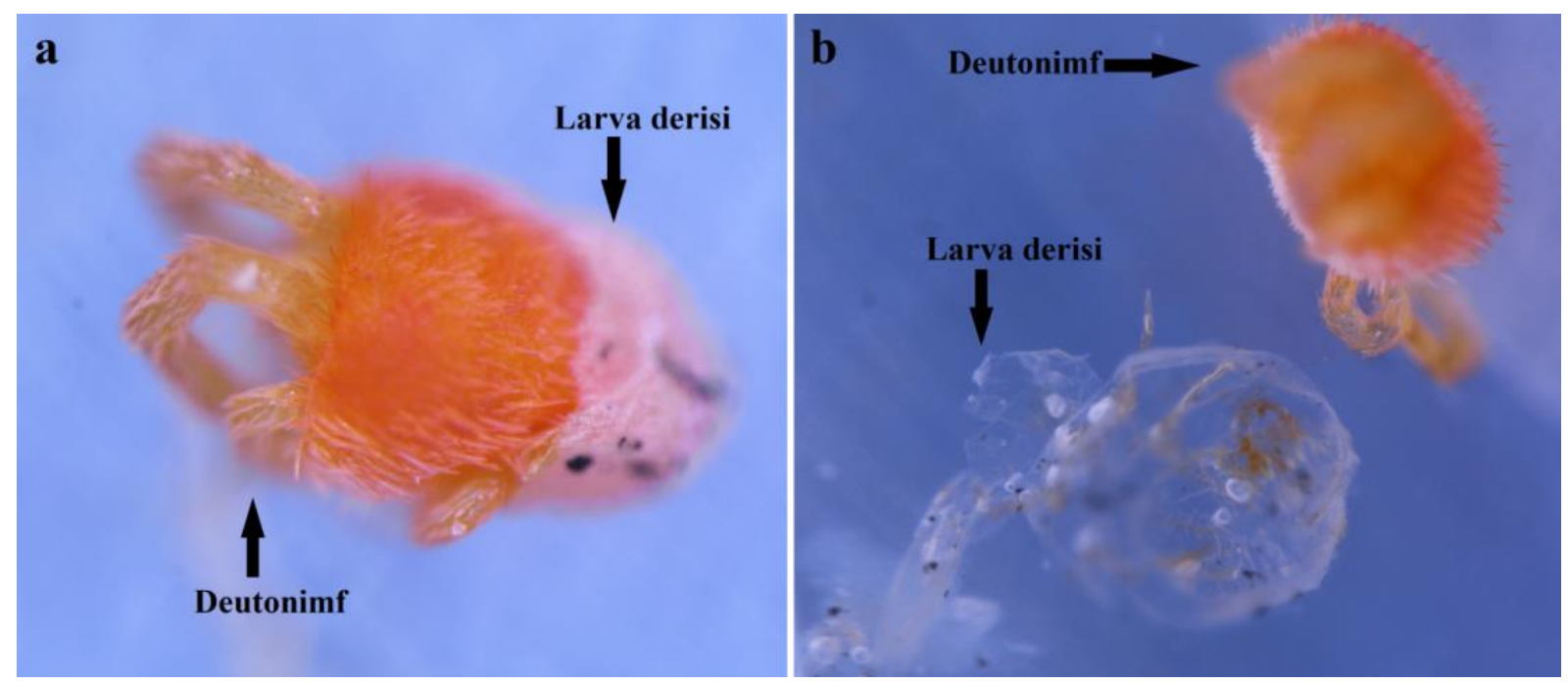

Şekil 3. Trombidioid deutonimfinin larva derisinden çıkışı 
Örneklerin ölçümleri ve fotoğraflar çekimleri Olympus BX63 DIC 1ş1k ve Nikon SMZ25 stereo mikroskoplarında yapılmıştır (Şekil 1 hariç verilen tüm fotoğraflar, çalışmada adı geçen örneklere aittir). Ölçümler mikrometre $(\mu \mathrm{m})$ cinsinden verilmiştir. Morfolojik terminoloji için Gabryś (1999) ve Mąkol (2007)'den yararlanılmıştır. İncelenen örnekler Erzincan Binali Yildırım Üniversitesi Fen Edebiyat Fakültesi, Biyoloji Bölümü'nde muhafaza edilmektedir (Kisaltmalar: $A L$ : Larvanın sukutum plağında bulunan 2. çift kıllar, $A M$ : Larvanın sukutum plağında bulunan 1. çift kıllar, $b s$ : Subkapitulum k1lı (veya hipostomal), $S$ : Larvada ve larva sonras1 fertlerde bulunan duyu k1lı, SD: Larva dorsal uzunluk ölçümü, SB: $S$ kılları arasındaki mesafe, $\sigma$ : Bacak genuda bulunan solenidiyum).

\section{Bulgular}

Aynı türe ait olduğu kesin olan larva ve deutonimflerden ikili teşhis yapılarak konaklar üzerindeki türler tanımlandı. Toplanan üç konak üzerindeki akarlardan üç ayrı tür teşhis edildi; Opilionid üzerinden Allothrombium sp., Rhagio sp. üzerinden Trombidium holosericeum, Musca domestica üzerinden alınanlar ise Trichotrombidium muscarum olarak teşhis edildi. Rhagio sp. ile Trombidium holosericeum arasındaki parazit konak ilişkisi Sevsay ve Buğa (2018)'de verilmiştir. Diğer iki konak parazit ilişkisi ise daha öncede Gabryś vd. (2011) tarafından verilmiştir.

Aşağıda, bu türlerin elde edilme süreçleri ve teşhiste önemli olan özellikleri verilmiştir.

Familya Trombidiidae Leach, 1815

Altfamilya Allothrombiinae Thor, 1935

Cins Allothrombium Berlese, 1903

Tür Allothrombium sp.

Muğla ilinden, üzerinde altmış tane beslenmiş ve beslenmemiş larva olan bir opilionid toplandı. Beslenmiş larvalardan sadece üç tanesi deutonimf evresine (Şekil 4.a) geçti. $\mathrm{Bu}$ geçiş 17-24 gün arasında gerçekleşti. Allothrombium cinsinin larvaları için önemli karakteristik özelliğe sahip olan, trokhanter, femur ve genuda k1 taşımayan palp (Şekil 4.b-c) ve II. bacakta iki sölenidyum taşıyan genu (Şekil 4.d-e) karakterleri, beslenmemiş (normal) larva ile atılmış larva derilerinde karşılaştırıldı. 


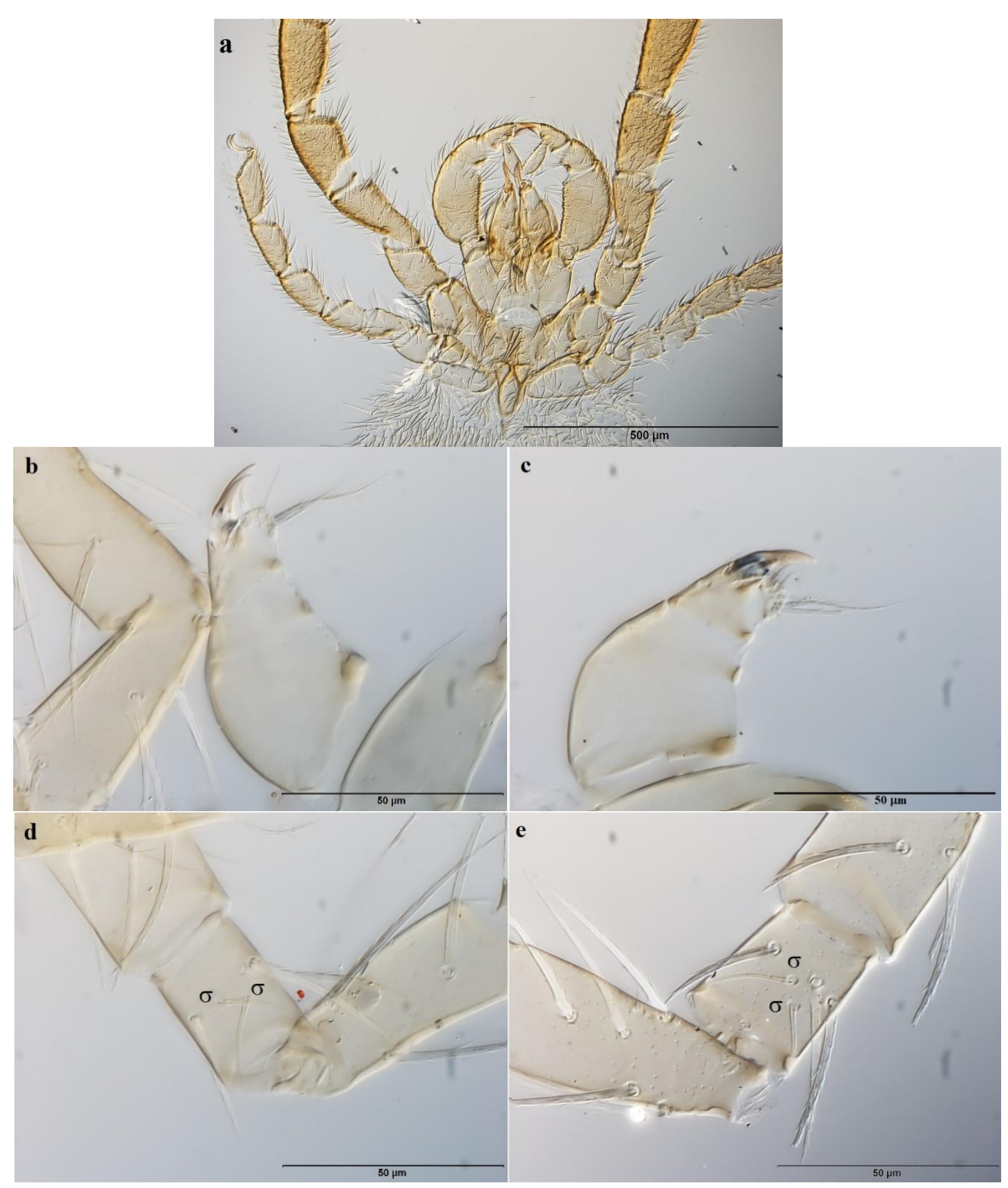

Şekil 4. Allothrombium sp.; a. Deutonimf b. Beslenmemiş larva palp c. Larva derisi palp d. Beslenmemiş larva II. bacak genu e. Larva derisi II. bacak genu 
Familya Trombidiidae Leach, 1815

Altfamilya Trombidiinae Leach, 1815

Cins Trombidium Fabricius, 1775

Tür Trombidium holosericeum (Linnaeus, 1758)

Rhagio sp. üzerinden dört adet ektoparazit Ordu ilinden toplandı (Sevsay ve Buğa, 2018). Beslenmemiş bir larvanın preparatı yapıldı, diğer üç larva ise yaşam şişesine konuldu. Bunlardan bir tanesi beş gün sonra protonimf, onaltı gün sonra ise deutonimf evresine geçti (Şekil 5.a). Bir larva mantar hifleri tarafından enfente olduğu için preparatı yapılamadi. Fakat deutonimf evreye geçerken larvanın bıraktığ 1 deri kullanıldı̆̆ için örnek kaybı minimuma indirildi. Trombidium larvaları için karakteristik olan $b s$ kılı (Şekil 5.b-c), özel kıllar taşıyan genu parçası ve boydan boya bölünmüş tibiya tırnağı olan palp (Şekil 5.de), dorsalde yer alan skutum parçası (Şekil 6.a-b) ayrıca III. tarsusun uç kısmında bulunan hançer benzeri yardımcı kıl (Şekil 6.c-d) hem normal hem de atılmış deride incelendi.

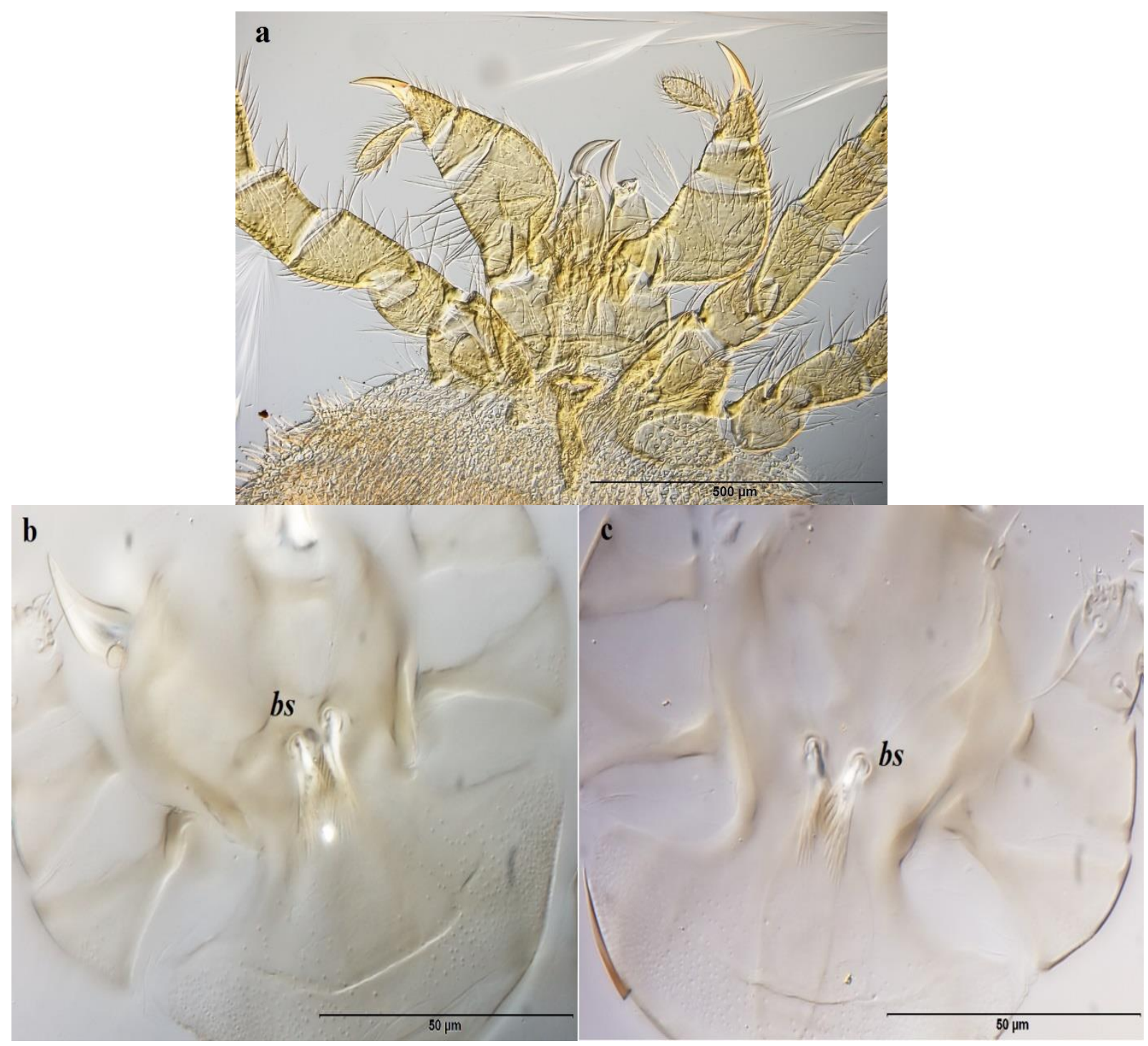




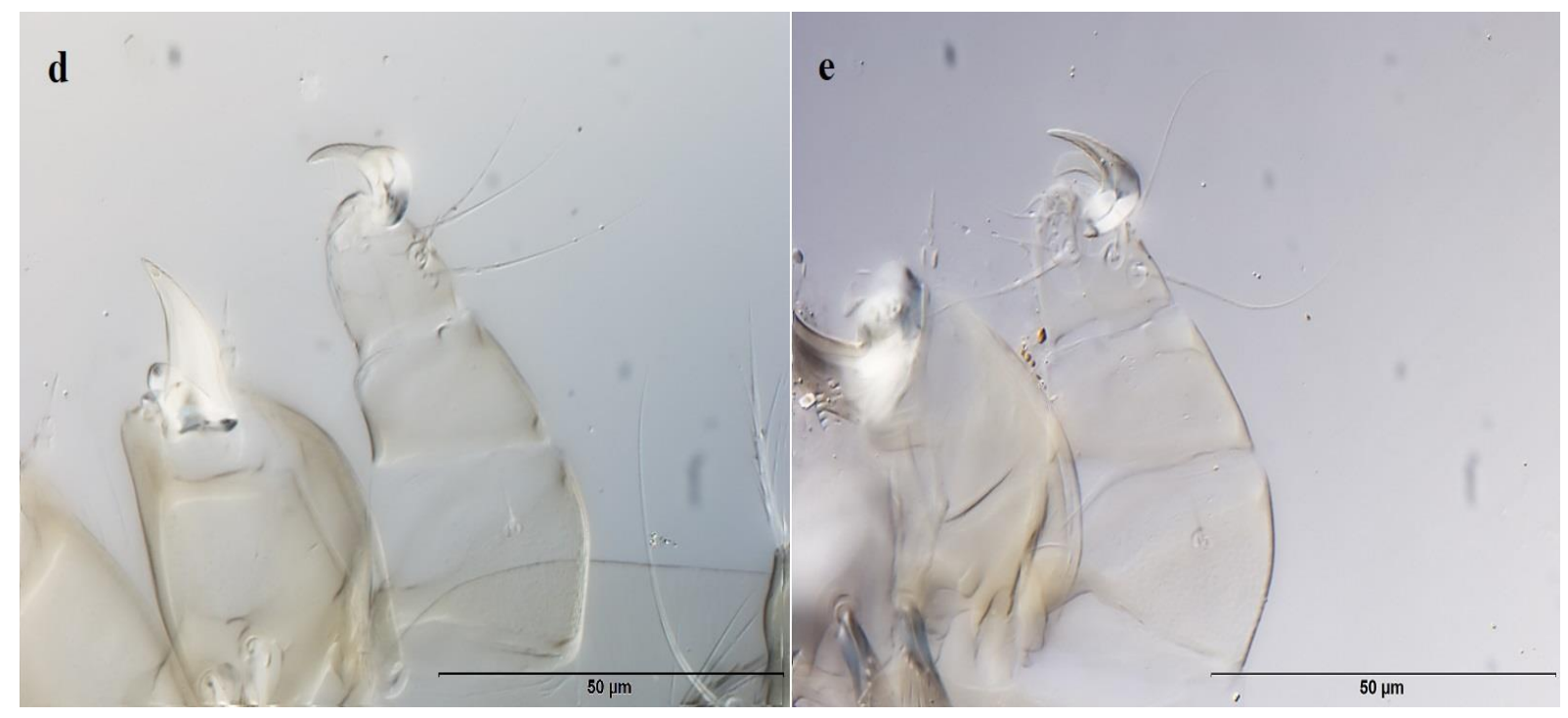

Şekil 5. Trombidium holosericeum; a. Deutonimf b. Beslenmemiş larvada gnathosomadaki $b s$ k1lı c. Larva derisinde gnathosomadaki $b s$ kılı d. Beslenmemiş larva palp e. Larva derisi palp

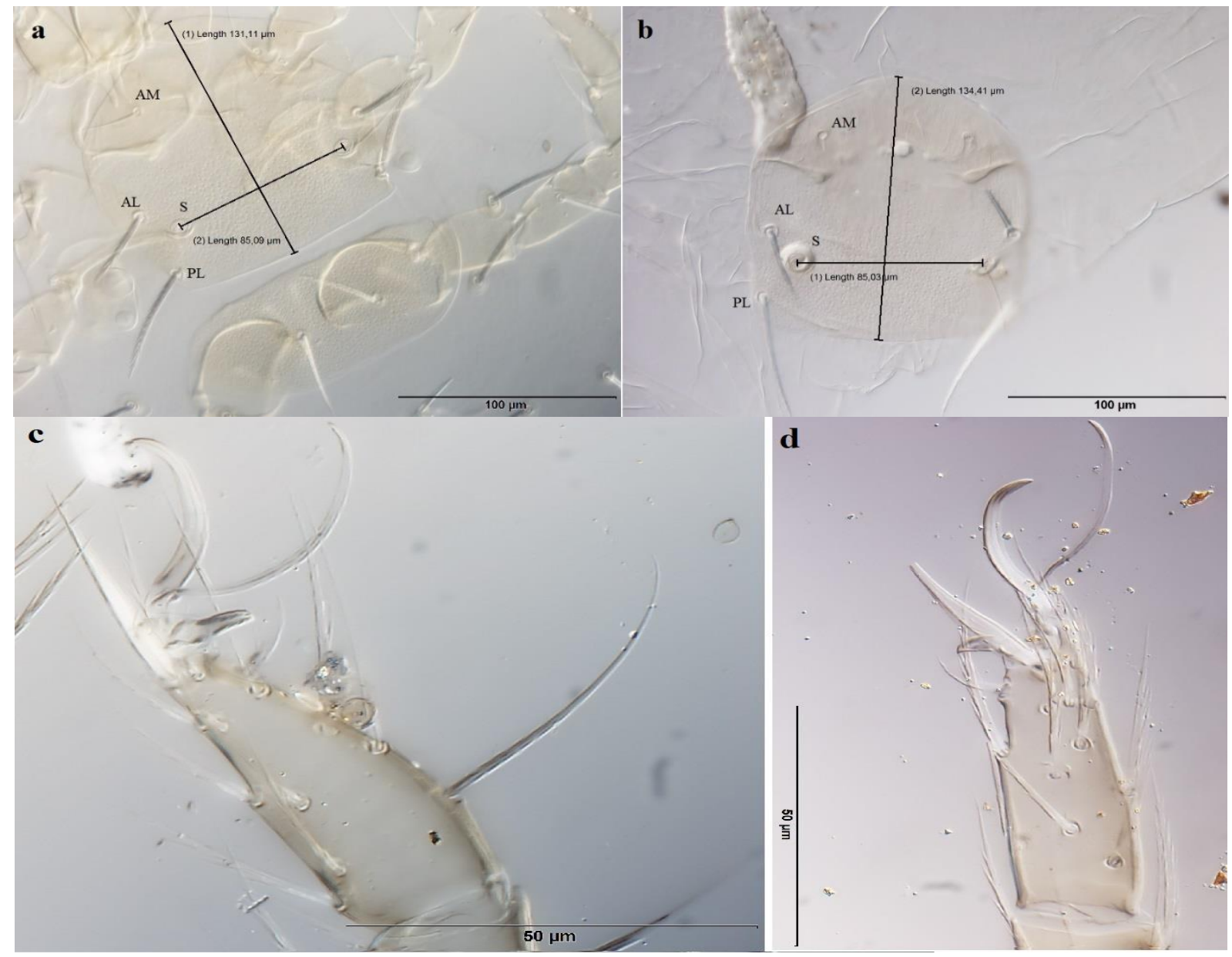

Şekil 6. T. holosericeum; a. Beslenmemiş larva skutum b. Larva derisi skutum c. Beslenmemiş larva III. bacak tarsus b. Larva derisi III. bacak tarsus 
Familya Microtrombidiidae Thor, 1935

Altfamilya Microtrombidiinae Thor, 1935

Cins Trichotrombidium Kobulej, 1951

Tür Trichotrombidium muscarum (Riley, 1878)

Musca domestica üzerinden dokuz adet ektoparazit larva Tunceli'den toplandı. Bu larvalardan sadece üç tanesi beslenmemiş olduğundan, altı tanesi yaşam şişesine konuldu. Bunlardan iki tanesi 2-3 gün sonra protonimf, 9-10 gün sonra ise deutonimf olmayı başardı. Deutonimfin gnathosomasındaki krista metopikanın posteriyor kısmı gelişmemiş olarak gözlemlendi (Şekil 7.a). Larvanın dorsalinde yer alan skutum hem larva hem de bırakılmış deri ile karşılaştırıldı (Şekil 7.b-c).

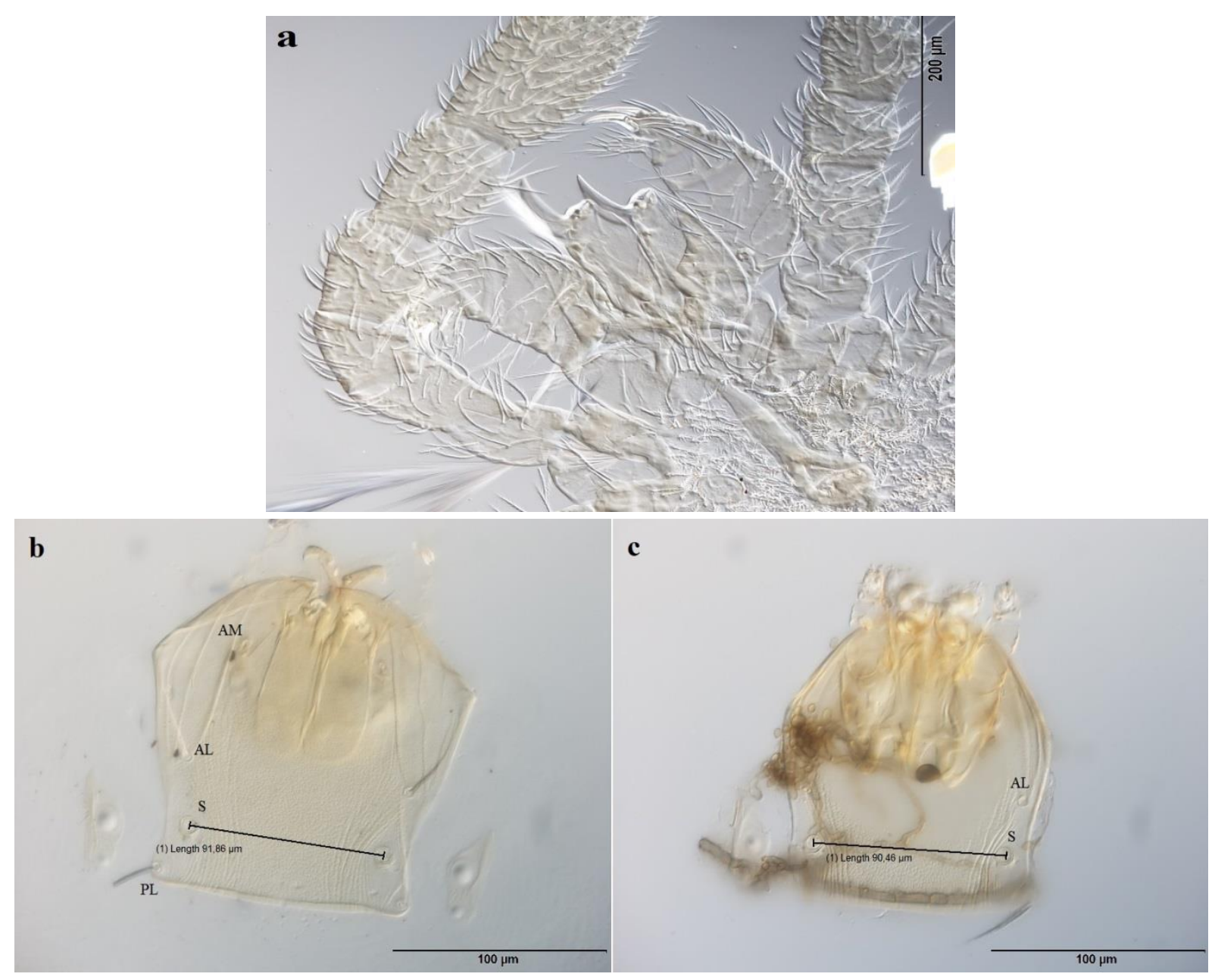

Şekil 7. Trichotrombidium muscarum; a. Deutonimf gnathosoma b. Beslenmemiş larva skutum c. Larva derisi skutum

Aynı konaklar üzerinden alınarak preparatı yapılan beslenmemiş larvalar ile beslenmiş larva derilerinin karşılaştırılması sonucunda; skutum, skutellum gibi yapıların şekil ve büyüklükleri, bazı önemli dorsal-ventral k1lların konum, uzunluk, dalcık durumları, bacak ve palplerde bulunan özel kılların sayısı, konumu ve şekli gibi teşhis için önemli morfolojik karakterlerin birbiriyle aynı olduğu görüldü 
(Şekil; 4.b-e, 5.b-e, 6.a-d, 7.b-c). Larva derileri ile beslenmemiş larvalar kıyaslandı ve aynı oldukları gözlemlendi. Böylece konaktan değerlendirilen tüm akarların aynı tür olduğu farklı bir türün parazit olarak konakta bulunmadığı anlaşıldı.

\section{Tartışma}

Allothrombium sp. larva derileri ve beslenmemiş larvalarının, tür seviyesinde belirleyici ve önemli karakterleri karşılaştırıldığında; palp tibiya ve tarsusta sayıs1 ve konumu aynı sayıda ve konumda oldukları görüldü (Şekil 4.b-c). Yine Allothrombium cinsini diğer cinslerden ayırt ederken kullanılan II. bacak genusunda bulunan 2 sölenidyum $(\sigma)$ kılı her iki örnekte de aynı şekil ve konumda gözlemlendi (Şekil 4.d-e).

\section{T. holosericeum' $u$ diğer Trombidium} türlerinden ayırt eden $b s$ kılının 11-15 parmaksı çıkıntılı oluşu ve pozisyonu yine her iki örnekte tamamen aynıdır (Şekil 5.bc). Hatta genellikle zor görülen $b s$ k1lı ve palp tarsusundaki k1llar, larva derisi örneklerinde daha belirgin ve nettir (Şekil 5.c, e). T. holosericeum'un dorsalde bulunan skutum ve skutellum yapılarında; beslenmemiş larva skutumu (Şekil 6.a) beşgen, gözenekli, SD $(131,11 \mu \mathrm{m})$, SB $(85,09 \mu \mathrm{m})$ iken larva deri örneklerinde (Şekil 6.b) gözenekler yapısı kaybolmamış, SD $(134,41 \mu \mathrm{m}), \mathrm{SB}(85,03 \mu \mathrm{m})$ 'dir. Aynı zamanda $A M, A L, S$ ve $P L$ killarının kalınlık, uzunluk ve dalcıklanma şekilleri de birebir uyuşmaktadır (Şekil 6.a-b). Örneklerin, bacak ketotaksileri kıyaslandığında da III. bacak tarsus'unda bulunan indirgenmiş tırnak, hançer benzeri küçük kıl ve diğer normal kıllar her iki örnekte aynıdır (Şekil 6.c-d).
T. muscarum larvasindan deutonimf evresi ilk defa 1951'de Kobulej tarafindan elde edilmiştir. Bu çalışma ile bu türün larvadan deutonimf evresi ikinci kez gözlemlendi (Şekil 7.a). Musca domestica üzerinden alınan T. muscarum örneklerinden sadece bir tanesinden deri preparasyonu gerçekleştirildi. Örnek kötü durumda olmasına rağmen, deri yapıları teşhis ve ölçümler için yeterince bilgi verdi. Karşılaştırma için dorsalde skutumlara bakıldığında, larva derisine ait skutumun ön kenar çıkıntılarının preparasyondan kaynaklı hatalardan dolayı katlandığ 1 görüldü (Şekil 7.b). Skutumdaki kılların konumu, şekli ve cinsin özelliklerinden olan enine çizgilenmeler iki örnekte de aynıdır (Şekil 7.b-c). Beslenmemiş larvaya ait SB $(91,86 \mu \mathrm{m})$ (Şekil 7.b) iken, larva derisi SB (90,46 $\mu \mathrm{m})$ 'dir (Şekil 7.c). Aynı zamanda her iki örnekte de lensi çevreleyen plağın özel şekli, gözlerin lens büyüklükleri ve hatta ön lensin skutumun $S$, arka lensin skutumun $P L$ kılı ile benzer hizada oluşları da tamamen aynı olarak gözlemlendi (Şekil 7.b-c).

Böylece aynı konaktan alınan, beslenmemiş larvalar ile deutonimflerin aynı tür oldukları tespit edildi. Larva derisi kullanılmasa idi, aynı konaktan olan beslenmemiş larvalar ile deri değiştiren deutonimflerin aynı tür olduğu kesin olarak söylenemezdi. Çünkü bir konağa, birden fazla türün parazit olarak tutunma ihtimali her zaman vardır.

Larva derisi kullanımının önemini bir kaç durum için değerlendirdiğimizde; konak üzerindeki incelenecek larva sayısı fazla olduğunda, larva derisi sadece bu larvalar ve elde edilen deutonimfler arasındaki ilişkiyi (aynı tür olup olmadığını) kanıtlamak için kullanılabilir. Konak üzerinde larva sayısının az olduğu 
durumlarda, larva derisi larvalarla birlikte çizim ve morfometrik ölçüm tablosu için de kullanılabilir. Son olarak konakta sadece bir parazit larvanın bulunduğu durumlarda larva derisi daha çok önem kazanmaktadır. İncelemek için sadece bir deutonimf ve bunun attığ 1 larva derisi bulunacağından, larva karakterlerinin gözlemi sadece atılan deriden yapılabilir.

Larva derisinin değerlendirilmesiyle ilgili karasal parasitengonada yapılan az sayıda çalışma vardır. Welbourn (1985) trombidioid akarların filogenetiği üzerine yaptığı bir çalışmada, larva derisini değerlendirmiş ancak taksonomik açıdan detaylı bir değerlendirme için uygun olmadığını söylemiştir. Erythraeoid üzerine yapılan bir çalışmada ise morfometrik ölçümlerde üç larva derisinden faydalanılmıştır (Mąkol vd., 2011). Ayrıca Moniuszko vd. (2018) trombiculid üzerine yaptıkları çalışmalarında, larvaların sayısının az olması durumunda veya zarar görmesi halinde larva derisinin kullanılabileceğinden bahsetmiştir. Wohltmann ve Went (1996) Valgotrombium major'un biyolojisi üzerine yaptıkları çalışmada larvaları parazitlendirmiş, deri değişimini gözlemlemiş ancak bu derilerin preparasyonlarından bahsetmemişlerdir. Karasal parasitengona grubu haricinde, yaşam evreleri daha farklı olan oribatid türlerinde (Belba corynopus (Hermann, 1804), Metabelba parapulverosa Moritz, 1966, Metabelba papillipes Nicolet, 1855) nimf derilerine ağırlık verilmiş ve deriler bazı türlere özgü karakter olarak kullanılmıştır (Seniczak ve Seniczak, 2013).

Tüm bu sonuçlar karasal parasitengona üyelerinin teşhisinde, deutonimf evresine geçiş sırasında bırakılan larva derilerinin, hem çizimde hem de ölçümlerde kullanılabileceği göstermiştir. Böylece araziden, aynı konaktan hem larva hem de larva sonrasis safhalar değerlendirileceğinden türün biyolojisi hakkında yanlış bilgilendirme yapılması ve bilgi karmaşıklığı giderilecektir.

\section{Teșekkür}

Bu çalışma, 2-8 Eylül 2018 tarihleri arasında Antalya'da (Türkiye) düzenlenen $X V$. International Congress of Acarolgy (XV. ICA)'nde poster olarak sunulmuştur. Çalışmanın bir kısım materyalini Türkiye Bilimsel ve Teknolojik Araştırma Kurumu (TÜBİTAK) tarafindan desteklenen 217Z184 numaralı projeden elde edilen örnekleri oluşturmaktadır. Desteklerinden ötürü TÜBİTAK'a teşekkür ederiz.

\section{Kaynaklar}

Gabryś, G. 1996. "Microtrombidiidae (Acari, Actinedida) of Poland. Annales of the Upper Silesian Museum", Entomology, 6-7: 145-242.

Gabryś, G., Felska, M., Kłosińska, A., Staręga, W. ve Mąkol, J. 2011. "Harvestmen (Opiliones) as hosts of Parasitengona (Acari: Actinotrichida, Prostigmata) larvae", Journal of Arachnology, 39(2): 349-351.

DOI: $\underline{10.1636 / C P 10-93.1}$

Kobulej, T. 1951. "Eine neue Trombidiiden Art, Trichotrombidium muscae gen et sp. $\mathrm{n}$. (Microtrombidiinae Sig Thor, 1935)", Acta veterinaria Academiae scientiarum hungaricae, 1 (1): 83-105. 
Mąkol, J. 2007. "Generic level review and phylogeny of Trombidiidae and Podothrombiidae (Acari: Actinotrichida:Trombidioidea) of the World", Annales Zoologici, 57 (1): 1-194.

Mąkol, J. ve Sevsay, S. 2011. "Notes on the genus Dolichothrombium (Acari: Prostigmata: Trombidiidae) with description of a new species", Zootaxa, 2971: 1-16.

Mąkol, J. ve Wohltmann, A. 2012. “An annotated checklist of terrestrial Parasitengona (Actinotrichida: Prostigmata) of the World, excluding Trombiculidae and Walchiidae", Annales Zoologici, 62 (3): 359-562.

Mąkol J, Wohltmann A. 2013. "Corrections and additions to, the checklist of terrestrial Parasitengona (Actinotrichida: Prostigmata) of the world, excluding Trombiculidae and Walchiidae", Annales Zoologici. 63: 15-27.

Mąkol, J., Gabryś, G. ve Łaydanowicz, J. 2011. "Leptus phalangii (De Geer, 1778) (Acari: Actinotrichida: Prostigmata) redescription, ecology and taxonomic notes on its relatives", Annales Zoologici, 61 (3): 535-546.

\section{DOI: $\underline{10.11158 / \text { saa.14.2.6 }}$}

Moniuszko, H., Felska, M., Mąkol, J. 2018 Evidence for co-invasion events: different chigger species (Actinotrichida, Trombidioidea: trombiculidae) share a host", Experimental and Applied Acarology, 76(1): 29-39.

DIO: $\underline{10.1007 / \mathrm{s} 10493-018-0293-4}$

Robaux, P. 1974. "Recherches sur le developpement et la biologie des acariens
'Thrombidiidae'. Memoires du Museum national d'histoire naturelle Paris (n.s.). Ser. A”, Zoologie, 85: 1-186.

Seniczak, S. ve Seniczak, A. 2013. "Morphology of juvenile stages and ontogeny of three species of Damaeidae (Acari: Oribatida)", International Journal of Acarology, 39(2), 160-179.

\section{DOI:}

\section{$\underline{10.1080 / 01647954.2012 .747567}$}

Sevsay, S. 2017. "A checklist of the Erythraeoidea and Trombidioidea (Actinotrichida: Prostigmata) of Turkey", Türkiye Entomoloji Bülteni, 7 (2): 175-196.

Sevsay, S. ve Buğa, E. 2018. “Trombidiid (Acari: Trombidiidae) Akarlar tarafindan parazitlenen konakçılar", Erzincan Üniversitesi Fen Bilimleri Enstitüsü Dergisi, 11-3.

Walter, D.E. ve Krantz, G.W. 2009. "Collecting, rearing, and preparing specimens. In: Krantz, G.W. \& Walter, D.E. (eds.) A manual of Acarology. 3th edition", Texas Tech University Press, pp. 83-96.

\section{DOI: $\underline{10.1653 / 024.092 .0323}$}

Welbourn, W.C. 1985. "Phylogenetic studies of trombidioid mites dissertation", $\mathrm{PhD}$ Thesis, The Ohio State University, 196.

Wohltmann, A. ve Wendt, F. E. 1996. "Observations of the biology of two hygrobiotic trombidiid mites (Acari: Prostigmata: Parasitengona) with special regard to the recognition and parasitism tactics", Acarologia, 37: 31-44.

Wohltmann, A., Gabryś, G. ve Mąkol, J. 2006. "Terrestrial parasitengonain habiting 
transient biotopes, (In: R. Gerecke Ed.),

Vol. 7/2-1, Chelicerata, Acari I. Spektrum

Elsevier, München", Süßwasserfaunavon

Mitteleuropas, pp. 158-240. 